\title{
Identificação dos colágenos I, III, IV e $\alpha$-SMA e participação dos miofibroblastos no processo fibrótico das endometroses equinas
}

\author{
[Identification of collagens types I, III, IV and $\alpha$-SMA and the participation of myofibroblasts \\ in the fibrotic process in equine endometrosis] \\ L.D. Costa, M.C. Dias, M.A. Alvarenga, J.L. Sequeira \\ Universidade Estadual Paulista "Júlio de Mesquita Filho" - Botucatu, SP
}

\begin{abstract}
RESUMO
A endometrose é uma alteração degenerativa das glândulas uterinas e do estroma circundante, caracterizada pelo arranjo periglandular de miofibroblastos e pela deposição de matriz extracelular (ECM). O presente trabalho objetivou avaliar a expressão de colágenos tipos I, III e IV e $\alpha$-actina de músculo liso ( $\alpha$-SMA) nas endometroses equinas, procurando esclarecer a participação dos miofibroblastos na progressão desses processos. Foram utilizadas 24 biópsias uterinas com diagnóstico de endometrose, recebidas pelo Serviço de Patologia Veterinária e de Reprodução Animal da FMVZ, Unesp, Botucatu, SP. Cortes histológicos foram submetidos às técnicas histoquímicas de tricrômico de Masson, picrosirius red sob luz polarizada e ácido periódico de Schiff (PAS) e imuno-histoquímicas para os três tipos de colágeno citados e $\alpha$-SMA. Ainda, traçou-se um paralelo entre a técnica de picrosirius red e a imunomarcação dos colágenos tipos I e III. A análise histológica revelou que as fibras de colágeno denso correspondem ao colágeno tipo I, predominantes nas endometroses inativa e inativa destrutiva. As fibras de colágeno frouxo correspondem ao colágeno tipo III, predominantes nas endometroses ativas e ativas destrutivas. Nesses mesmos processos, a membrana basal revelou espessamento, aparentemente não relacionado ao colágeno tipo IV, e uma maior imunomarcação de miofibroblastos periglandulares em relação às endometroses inativa e inativa destrutiva. Dessa forma, nota-se que os miofibroblastos estão relacionados ao aumento na deposição de colágeno tipo III nos ninhos fibróticos ativos.
\end{abstract}

Palavras-chave: égua, endometrose, colágeno, miofibroblastos, imuno-histoquímica

\begin{abstract}
Endometriosis is a degenerative change of the uterine glands and surrounding stroma, characterized by periglandular arrangement of myofibroblasts and deposition of extracellular matrix (ECM). The aim of this study was to evaluate the expression of collagen type I, III and IV and $\alpha$-smooth muscle actin ( $\alpha$-SMA) in equine endometriosis, and investigate the role of myofibroblasts in the progression of these processes. A parallel was made with histochemical techniques of Masson's trichrome, Picrosirius Red under polarized light and Periodic Acid-Schiff (PAS). Twenty four uterine biopsies received by the Veterinary Pathology Service and Animal Reproduction of FMVZ, UNESP, Botucatu, SP, were diagnosed with endometriosis. Histological analysis revealed that the orange dense collagen fibers correspond to type I collagen, being prevalent in inactive and inactive destructive endometriosis. The green loose collagen fibers correspond to type III collagen, and are predominant in active and active destructive endometriosis. In the same processes, a greater amount of periglandular myofibroblasts were observed in comparison to inactive and inactive destructive endometriosis. The presence of these cells in active processes are strongly related to an increased deposition of collagen type III in fibrotic nests. Regarding the basement membrane, the active destructive and active endometriosis shows thickening, apparently not related to an increase in expression of type IV collagen. The active destructive and inactive destructive endometriosis exhibited disruption areas in type IV collagen fibers. Thus, it is noted that the myofibroblasts are related to increased deposition of type III collagen in active fibrotic nests.
\end{abstract}

Keywords: mare, endometriosis, collagen, myofibroblasts, immunohistochemistry

Recebido em 29 de julho de 2016

Aceito em 11 de fevereiro de 2017

E-mail: leonardomvet@gmail.com 


\section{INTRODUÇÃO}

A endometrose é uma alteração degenerativa das glândulas uterinas e do estroma circundante, associada à idade e diretamente relacionada com problemas de fertilidade em éguas (Ricketts e Alonso, 1991). O arranjo periglandular de miofibroblastos e a deposição de matriz extracelular (ECM) são características importantes da endometrose (Walter et al., 2001). Durante o desenvolvimento desses processos, os fibroblastos expressam vários fatores de diferenciação muscular, como alfaactina de músculo liso ( $\alpha$-SMA), tropomiosina e desmina, e foram, portanto, identificados como miofibroblastos (Sappino et al., 1990). Além disso, os miofibroblastos expressam também várias proteínas da ECM, como fibronectina, laminina, colágeno tipo IV e tenascina (Hanamura et al., 1997).

A presença desse tipo celular já havia sido descrita anteriormente nas amostras de endométrio equino fibrótico examinadas por microscopia eletrônica de transmissão (Evans et al., 1998). Os miofibroblastos contribuem para a alteração das propriedades do tecido afetado, havendo evidências de que a produção de colágeno pelos fibroblastos seja uma consequência da diferenciação desses em miofibroblastos (Petrov et al., 2002).

A etiologia e a patogenia da endometrose são desconhecidas. Uma hipótese concebida para a patogênese da endometrose baseia-se nos achados morfológicos e estabelece as fases de evolução do processo fibrótico, denominando-as, de forma sequencial, como fibrose ativa, fibrose ativa destrutiva, fibrose inativa e fibrose inativa destrutiva (Hoffmann et al., 2009).

Hoffmann et al. (2009) sugerem que a proliferação de células estromais e sua diferenciação em miofibroblastos, assim como o aumento da síntese de ECM, respondem à ação sinergística e autoinduzida de mediadores, resultando em fibrose periglandular. Além disso, a capacidade dos miofibroblastos para liberar várias enzimas que regulam a homeostase da ECM pode contribuir para a destruição progressiva da lâmina basal, resultando em um acúmulo dessa matriz, o que, por sua vez, é capaz de manter o processo fibrótico (Walter et al., 2001). Ademais, Hanada et al. (2014) postulam que a presença de células epiteliais degeneradas ou necróticas se deve, principalmente, ao dano causado à membrana basal, resultando em contato direto entre as células estromais e epiteliais, bem como a interações entre a ECM fibrótica e células epiteliais glandulares. A partir da interação desses diversos fatores, a concomitância do processo de endometrite seria uma das causas da ativação metabólica das células estromais fibróticas (Hoffmann et al., 2009).

Um método histoquímico utilizado para a avaliação do tecido conjuntivo é o picrosirius red, que diferencia os tipos de colágeno pela birrefringência das fibras em microscópio óptico de luz polarizada. Assim, diferentes tonalidades são observadas conforme o tipo de arranjo molecular presente (Junqueira et al., 1978). Entretanto, no início do desenvolvimento desse método, ficou evidente que a espessura do corte histológico é de grande importância na cor e intensidade da birrefringência exibida pelo colágeno. Essa é a razão pela qual não se correlacionou uma especificidade entre a coloração de picrosirius red e os diferentes tipos de colágeno (Junqueira et al., 1978).

Estudos imuno-histoquímicos para tipificação das fibras de colágeno ainda são escassos no que diz respeito ao endométrio equino. Até o momento, a tipificação do colágeno endometrial nas éguas restringe-se à detecção da presença do colágeno tipo IV nas diversas fases do ciclo estral (Mansour et al., 2003) e a um único estudo que relaciona essa tipificação à endometrose (Walter et al., 2001), porém sem considerar as etapas da patogênese do processo (Hoffmann et al., 2009).

Deve-se ressaltar que os diferentes métodos utilizados para a determinação da distribuição e das características do colágeno presente no endométrio fibrótico têm levado a resultados discrepantes. Os autores que utilizaram o método do picrosirius red sob luz polarizada relatam que a fibrose periglandular está associada ao aumento da quantidade de colágeno fibrilar periglandular (Evans et al., 1998). Porém, quando o método imuno-histoquímico foi empregado, o tipo de colágeno observado na fibrose ao redor das estruturas glandulares, inclusive envolvendo as células estromais da região, foi o do tipo IV, tipo esse restrito à membrana basal (Walter et al., 2001). 
Assim, o entendimento do processo de evolução da endometrose depende do reconhecimento morfológico do tipo de reação envolvida e dos elementos que a compõem. A participação dos miofibroblastos e sua relação com o tipo de colágeno presente, nas diferentes etapas que têm sido consideradas no processo de endometrose, podem auxiliar não só na compreensão da fibrose endometrial, mas também futuramente na pesquisa de linhas terapêuticas.

O presente trabalho objetiva avaliar as lesões fibróticas endometriais, por meio da identificação do tipo de colágeno presente e da participação dos miofibroblastos nos tipos de endometrose propostos por Hoffmann et al. (2009), a fim de estabelecer a relação entre a matriz e os tipos celulares em cada etapa do processo.

\section{MATERIAL E MÉTODOS}

No presente estudo, foram utilizadas 24 biópsias endometriais com diagnóstico de endometrose, provenientes dos arquivos do serviço de Patologia Veterinária da Faculdade de Medicina Veterinária e Zootecnia - FMVZ/Unesp Campus de Botucatu - SP. O trabalho foi aprovado pela Comissão de Ética no Uso de Animais (Ceua) dessa faculdade, protocolo $n^{0} 134 / 2014-C E U A$.

Todas as biópsias foram submetidas ao mesmo tipo de processamento laboratorial: fixação em Bouin e inclusão em parafina. Foram obtidos cortes de quatro micrômetros de espessura dos blocos, os quais foram corados pelos métodos de hematoxilina e eosina, tricrômico de Masson, picrosirius red e ácido periódico de Schiff (PAS). A identificação das alterações endometriais e a classificação das lesões seguiram as descrições de Hoffmann et al. (2009), em que se utilizaram endométrios sadios como controle, obedecendose os critérios de Kenney e Doig (1986).

Para a detecção de colágenos I, III e IV, realizouse recuperação antigênica por digestão enzimática em pepsina $1 \%, \mathrm{pH}$ 1,8 (pepsina 1:10.000 NF - Nuclear, SP, Brasil). As etapas seguintes foram o bloqueio da peroxidase endógena em solução de água oxigenada $3 \%$ e o bloqueio de sítios inespecíficos com leite desnatado a $3 \%$. Realizou-se a incubação com $100 \mu \mathrm{L}$ do anticorpo primário, na diluição de 1:2000, para colágeno tipo I (coelho anticolágeno I bovino, IgA, Ref. 20121, Novotec, França); 1:1000, para colágeno tipo III (coelho anticolágeno III bovino, IgA, Ref. 20321, Novotec, França); e 1:500, para colágeno tipo IV (coelho anticolágeno IV humano, IgG, ab115261, Abcam, Reino Unido) em câmara úmida, durante $18 \mathrm{~h}$, em temperatura de $4^{\circ} \mathrm{C}$.

Nos cortes em que foram aplicados o anticorpo anti- $\alpha$-SMA, a recuperação antigênica foi feita sob calor úmido em Pascal (Dako, S2800-1) com citrato a $10 \mathrm{mM}, \mathrm{pH} 6,0$. Em seguida, realizou-se o bloqueio de ligações inespecíficas com leite desnatado a 3\%. Logo após, aplicaram-se $100 \mu \mathrm{L}$ do anticorpo anti- $\alpha$-SMA (cod. M0851, Clone 1A4, Dako), na diluição de 1:1250, com tempo de incubação de 18 horas, em câmara úmida a $4^{\circ} \mathrm{C}$.

Posteriormente, todos os cortes foram incubados com o anticorpo secundário HistoFine ${ }^{\circledR}$ (Nichirei Bioscience, Japão), segundo instruções do fabricante. Finalmente, realizou-se revelação com o cromógeno DAB (3,3'-diaminobenzidina Liquid DAB Cromogen ${ }^{\circledR}$ - Dako, EUA). As lâminas foram contracoradas com hematoxilina de Harris.

Para avaliação dos cortes histológicos submetidos ao anticorpo anti- $\alpha$-SMA, os parâmetros considerados foram positividade de imunomarcação e quantidade de camadas celulares periglandulares positivas, associando-se ao tipo de endometrose estabelecida.

Para o estudo da distribuição dos tipos de fibras colágenas, foram analisadas a intensidade e a localização de fibras positivas para colágenos tipos I, III e IV, considerando-se os ninhos fibróticos, o estrato compacto e o esponjoso, mediante a utilização do endométrio hígido como grupo controle. Posteriormente, em cada biópsia, foi determinada a predominância do tipo de colágeno imunomarcado para cada tipo descrito na classificação de endometrose proposta por Hoffmann et al. (2009), obtendo-se a concordância estatística com os resultados histoquímicos do picrosirius red sob luz polarizada (coloração verde ou vermelhoalaranjada); e expressão imuno-histoquímica da $\alpha$-SMA pelas células presentes nos ninhos fibróticos. Para isso, o coeficiente Kappa foi calculado para analisar a concordância entre os resultados obtidos entre as técnicas, utilizando-se o software SAS, versão 9.3 (Statistical..., 2011). 


\section{RESULTADOS E DISCUSSÃO}

Considerando a classificação histológica proposta por Hoffmann et al. (2009), dos 24 casos de endometrose diagnosticados, seis foram incluídos na classificação de endometrose ativa (25\%); quatro na endometrose inativa (17\%); sete na endometrose ativa destrutiva (29\%); e sete como endometrose inativa destrutiva (29\%). A Tab.1 detalha os resultados obtidos na avaliação de cada parâmetro.

Nos cortes corados pela técnica histoquímica de tricrômico de Masson, foi observado que, nas endometroses ativas, os ninhos fibróticos revelaram fibras colágenas de espessura maior em relação às inativas.

Nas biópsias classificadas como endometrose ativa, os cortes corados pela técnica de picrosirius red e examinados sob luz polarizada revelaram que cinco em seis dessas amostras $(83 \%)$ apresentaram a predominância de fibras de colágeno do tipo frouxo por entre os túbulos glandulares no interior dos ninhos fibróticos. As amostras classificadas como endometrose inativa se caracterizaram por glândulas dilatadas com aspecto cístico, delineadas por fibras colágenas predominantemente densas em três dos quatro casos $(75 \%)$, tanto na porção periglandular quanto no interior dos ninhos fibróticos. Todos os casos diagnosticados como endometrose ativa destrutiva apresentaram deposição de colágeno frouxo predominante na porção interna dos ninhos fibróticos. Já ao redor dos ninhos, o colágeno do tipo denso predominou. Nas amostras de endometrose inativa destrutiva, houve predominância de colágeno do tipo denso na região periglandular e interna dos ninhos fibróticos, correspondendo a cinco dos sete casos (71\%). Ainda, foi observada uma deposição discreta de colágeno frouxo periglandular.

Tabela 1. Distribuição quantitativa dos tipos de endometrose, levando-se em consideração a predominância da deposição de colágeno frouxo ou denso nos ninhos fibróticos pela técnica de picrosirius red sob luz polarizada, e da imunoexpressão dos colágenos tipos I e III e $\alpha$-SMA

\begin{tabular}{cccccccc}
\hline Endometrose & $\begin{array}{c}\mathrm{N}^{\mathrm{o}} \text { de } \\
\text { casos }\end{array}$ & $\begin{array}{c}\text { Predomínio } \\
\text { colágeno } \\
\text { frouxo } \\
\text { (PRSLP) }\end{array}$ & $\begin{array}{c}\text { Predomínio } \\
\text { colágeno } \\
\text { denso } \\
\text { (PRSLP) }\end{array}$ & $\begin{array}{c}\text { Predomínio } \\
\text { colágeno } \\
\text { tipo I (IHQ) }\end{array}$ & $\begin{array}{c}\text { Predomínio } \\
\text { de colágeno } \\
\text { tipo III } \\
\text { (IHQ) }\end{array}$ & $\begin{array}{c}\text { Baixa } \\
\text { expressão } \\
\text { de } \alpha \text {-SMA } \\
\text { (IHQ) }\end{array}$ & $\begin{array}{c}\text { Alta } \\
\text { expressão } \\
\text { de } \alpha \text {-SMA } \\
\text { (IHQ) }\end{array}$ \\
\hline $\begin{array}{c}\text { Ativa } \\
\text { Ativa destrutiva }\end{array}$ & 7 & 5 & 1 & 1 & 5 & 4 & 2 \\
Inativa & 4 & 2 & 0 & 1 & 6 & 2 & 5 \\
Inativa destrutiva & 7 & 2 & 2 & 3 & 1 & 4 & 0 \\
Total & 24 & 16 & 8 & 3 & 4 & 6 & 1 \\
\hline
\end{tabular}

PRSLP: picrosirius red sob luz polarizada; IHQ: imuno-histoquímica.

Quanto à técnica histoquímica de PAS, nas endometroses ativas e ativas destrutivas, a marcação histoquímica da membrana basal das glândulas contidas nos ninhos fibróticos se deu em uma tonalidade púrpura, exibindo um espessamento considerável quando comparada às endometroses inativas e inativas destrutivas. Nestas, foram observadas apenas estrias róseas delgadas e fibrilares.

Para a avaliação imuno-histoquímica, o endométrio hígido foi utilizado como controle positivo. A imunoexpressão de colágeno tipo I nessas amostras revelou-se difusamente no estroma, principalmente no estrato esponjoso. No estrato compacto, a imunomarcação foi discreta. De forma geral, nas endometroses houve imunomarcação moderada e difusa de colágeno tipo I nos estratos compacto e esponjoso, não diferindo do endométrio hígido. Considerando a positividade nos ninhos fibróticos, oito biópsias apresentaram predominância desse tipo de colágeno, representando $25 \%$ das amostras. Dessas oito, três eram endometrose inativa; três inativas destrutivas; uma ativa; e uma ativa destrutiva. Nas endometroses ativa e ativa destrutiva, notou-se uma imunomarcação discreta nas fibroses periglandulares quando comparadas às endometroses inativa e inativa destrutiva, que revelaram marcação acentuada.

Assim como o colágeno tipo I, no endométrio hígido, a imunomarcação do colágeno tipo III apresentou-se difusa nos estratos compacto e esponjoso. As biópsias com diagnóstico de endometrose, bem como o grupo controle, apresentaram imunomarcação difusa. Dezesseis 
das 24 biópsias $(66,66 \%)$ revelaram predominância desse tipo de colágeno na porção interna dos ninhos fibróticos. Seis ativas destrutivas; cinco ativas; quatro inativas destrutivas; e uma inativa. Nas endometroses ativa e ativa destrutiva, foi detectada uma imunomarcação acentuada por entre as glândulas contidas no interior dos ninhos fibróticos. Já nas endometroses inativa e inativa destrutiva, a marcação restringiu-se à porção delimitadora do ninho fibrótico.

Tanto o endométrio hígido quanto as endometroses exibiram imunomarcação para o colágeno tipo IV restrito à membrana basal do epitélio luminal e glandular e de vasos sanguíneos. Nas amostras de endometrose, não foram observadas alterações de espessamento da camada de colágeno tipo IV da membrana basal. No entanto, nas endometroses ativa destrutiva e inativa destrutiva, foram observadas áreas de descontinuidade da fibra de colágeno tipo IV da membrana basal das glândulas contidas nos ninhos fibróticos.

A imunopositividade para $\alpha$-SMA no endométrio hígido demonstrou-se restrita à parede de vasos sanguíneos. Nas endometroses, além dos vasos sanguíneos, foi observada marcação positiva na região periglandular fibrótica de todas as biópsias. Considerando-se as células positivas na região periglandular, 16 biópsias $(66,67 \%)$ apresentaram imunomarcação discreta, com uma ou duas camadas de células, em glândulas individualizadas e por vezes em ninhos fibróticos, sendo seis inativas destrutivas; quatro inativas; duas ativas destrutivas; e quatro ativas. Oito biópsias revelaram imunomarcação acentuada $(33,33 \%)$, chegando até oito camadas de células periglandulares, sendo cinco ativas destrutivas; duas ativas; uma inativa destrutiva; e zero inativa.

As técnicas imuno-histoquímicas para colágenos tipos I e III apresentaram bom índice de concordância com a técnica histoquímica de picrosirius red sob luz polarizada (coeficiente Kappa $=0,625$ ). Quando comparada as mesmas técnicas imuno-histoquímicas com a de $\alpha$-SMA, o índice de concordância foi considerável (coeficiente Kappa=0,400).

Considerando-se a classificação das endometroses de Hoffmann et al. (2009), na coloração de tricrômico de Masson, as endometroses ativa e ativa destrutiva exibiram, no interior dos ninhos fibróticos, septos colagenosos mais espessos, se comparados às endometroses inativa e inativa destrutiva. No entanto, esse achado ficou mais bem detalhado na coloração de picrosirius red sob luz polarizada. Esta técnica demonstrou que não houve variação na distribuição das fibras colágenas estromais entre os diferentes tipos de endometrose descritas por Hoffmann et al. (2009), o que corrobora estudos anteriores (Walter et al., 2001). Apenas as biópsias com fibrose intersticial difusa revelaram uma deposição acentuada e difusa de fibras de colágeno denso.

Em todos os tipos de endometrose, a região periglandular exibiu o predomínio do colágeno denso, de arranjo fibrilar. Nas endometroses ativa e ativa destrutiva, o tipo de colágeno predominante nas amostras submetidas ao picrosirius red e examinadas sob luz polarizada na porção interna dos ninhos fibróticos é o que possui arranjo reticular, menos denso. Nas mesmas lesões, a marcação imuno-histoquímica na porção periglandular e na porção interna do ninho fibrótico foi mais intensa, respectivamente, para fibras de colágeno tipo I e tipo III. Em contrapartida, nas endometroses inativa e inativa destrutiva, nos cortes corados pela técnica de picrosirius red e examinados sob luz polarizada, o predomínio foi de fibras de colágeno denso, inclusive no interior dos ninhos fibróticos, havendo a correspondência imuno-histoquímica para o colágeno tipo I. Dessa maneira, nesse modelo de estudo de tecido patológico, confirma-se a hipótese pressuposta por Junqueira et al. (1978), que especularam, na avaliação de cortes histológicos, pela técnica de picrosirius red sob luz polarizada, de tecidos sadios ricos em colágeno, que as fibras amareladas observadas correspondem ao colágeno tipo I, enquanto as esverdeadas correspondem ao colágeno tipo III.

Tendo em vista a relação dos tipos de colágeno com a proposta de evolução do processo fibrótico endometrial proposto por Hoffmann et al. (2009), postulou-se que as endometroses ativas representam um processo fibrótico de características morfológicas e funcionais distintas das endometroses inativas. Isso se explica pelo envolvimento importante dos miofibroblastos, células metabolicamente ativas 
de alta capacidade pró-inflamatória e fibrogênica, nas endometroses ativas, que, por sua vez, estão relacionados à deposição de colágeno tipo III, frouxo. As endometroses inativas demonstraram uma baixa expressão de $\alpha$-SMA pelas células que circundam os ninhos fibróticos e estão relacionadas ao colágeno tipo I, denso. Então, entende-se que os fatores envolvidos nesses tipos de fibroses não estejam vinculados aos miofibroblastos, mas a outros fatores não elucidados até o momento. A predominância de colágeno tipo I em 16,67\% das endometroses ativas e a de colágeno tipo III em $25 \%$ das endometroses inativas podem estar relacionadas ao processo de desenvolvimento e evolução do processo fibrótico, em que há a substituição gradativa do tipo de colágeno frouxo pelo denso.

Pesquisadores observaram espessamento da membrana basal nas endometroses ativas e ativas destrutivas, algumas vezes com rompimento dela (Hanada et al., 2014). Os resultados do presente estudo concordaram com a da referida pesquisa, havendo nitidamente espessamento e hialinização da membrana basal nas endometroses ativas, que são agravados nas endometroses ativas destrutivas. Nos processos inativos, observou-se o mantimento de sua espessura e, quando houve dilatação cística, um discreto espessamento quando comparados à membrana basal do endométrio hígido. Apesar de a causa desse dano à membrana basal ainda ser desconhecida, acredita-se que seja o fator principal para a instalação da fibrose periglandular, já que ocorre alteração na deposição de componentes da matriz extracelular ao redor da membrana (Hoffmann et al., 2009).

Até o momento, a detecção imuno-histoquímica do colágeno tipo IV no endométrio equino restringe-se a um estudo em biópsias endometriais sadias nas diversas fases do ciclo estral (Mansour et al., 2003), e há um único estudo relacionado à endometrose (Walter et al., 2001). Contudo, o presente trabalho é o primeiro a relacionar a avaliação imuno-histoquímica do colágeno tipo IV considerando as etapas da patogênese do processo proposto por Hoffmann et al. (2009).

Quanto à associação desse método imunohistoquímico à classificação das endometroses proposta por Hoffmann et al. (2009), foi notado que os quatro tipos mantiveram um padrão de positividade semelhante ao do endométrio hígido, revelando o colágeno IV da membrana basal do epitélio luminal e glandular e vascular, apresentando-se delgada e fibrilar. De acordo com Walter et al. (2001), os miofibroblastos periglandulares liberam ativamente colágeno tipo IV no processo fibrótico, o que poderia explicar o espessamento da membrana basal observado na avaliação histoquímica. No entanto, a avaliação imuno-histoquímica feita por este estudo não revelou espessamento da camada de colágeno tipo IV. Ademais, Hoffmann et al. (2009) detectaram, por imuno-histoquímica, uma alta deposição de laminina na membrana basal em endometroses ativas destrutivas, além da expressão intracelular dessa glicoproteína nas células periglandulares. Esses achados podem justificar o espessamento da membrana basal observado pela técnica histoquímica de PAS do presente estudo, não estando relacionados ao espessamento de camadas de colágeno tipo IV.

Nas endometroses ativa destrutiva e inativa destrutiva, foram detectadas áreas de descontinuidade de fibras de colágeno tipo IV da membrana basal nos ninhos fibróticos. Esse fato pode explicar a degeneração e a necrose de células epiteliais que caracterizam esses dois tipos de endometrose, por haver uma quebra da interação dessas células com a matriz extracelular por meio da membrana. Ainda, ratifica parcialmente os resultados obtidos pela técnica histoquímica de PAS de Hanada et al. (2014), em que se constataram áreas de descontinuidade nos processos ativos. Essa concordância parcial provavelmente se deve ao fato de esses autores não levarem em consideração a característica "destrutiva" da classificação de Hoffmann et al. (2009), mas sim apenas os tipos ativo e inativo.

As amostras de endometrose ativa destrutiva apresentaram maior expressão de $\alpha$-SMA, representando a maior parte das amostras fortemente positivas $(71,42 \%)$, em concordância com Hoffmann et al. (2009). As endometroses inativas apresentaram uma imunomarcação discreta, com até duas camadas de células positivas periglandulares ou ao redor de glândulas que aparentemente não apresentavam sinais de fibrose ao exame histológico. Hanada et al. (2014) acreditam que esse último achado pode ser importante na caracterização de estágios iniciais da endometrose ou para diagnosticar 
éguas que tenham predisposição à doença. A Fig. 1 demonstra alguns resultados da coloração histoquímica de PAS e imuno-histoquímica do colágeno tipo IV e $\alpha$-SMA.

Quando se comparou a imunoexpressão de $\alpha$ SMA com a dos colágenos tipos I e III, percebeu-se que os ninhos fibróticos que revelaram um número maior de células positivamente marcadas, observadas principalmente nas endometroses ativas destrutivas, demonstraram forte imunorreatividade para colágeno tipo III. Nas endometroses com imunomarcação discreta para $\alpha$-SMA, predominantemente inativas, houve predominância de positividade para colágeno tipo I. A Fig. 2 demonstra um comparativo entre as técnicas imuno-histoquímicas dos colágenos tipos I e III e da $\alpha$-SMA e a técnica histoquímica de picrosirius red sob luz polarizada.

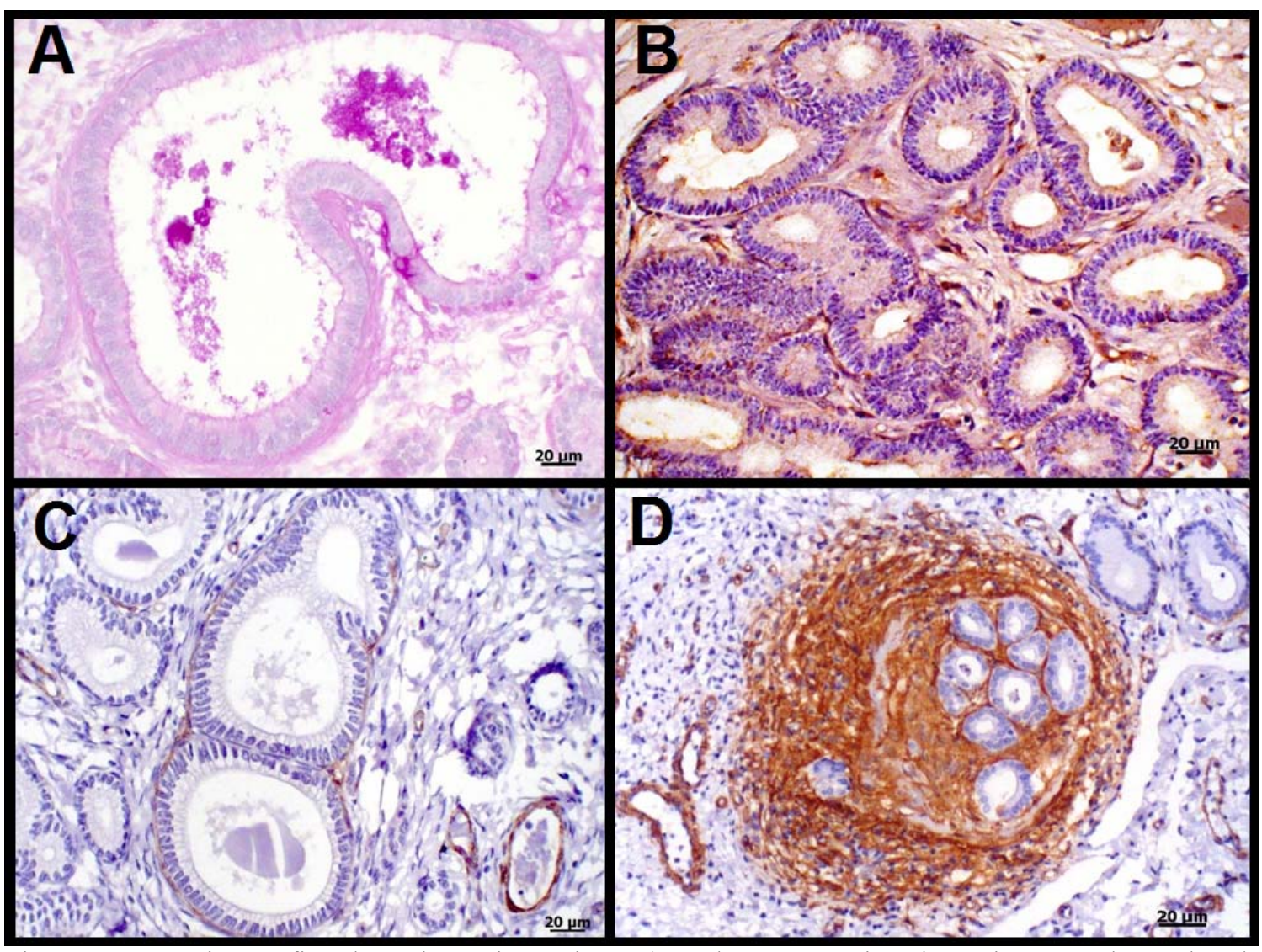

Figura 1. Fotomicrografias de endométrio equino. A) Endometrose ativa destrutiva. Membrana basal apresentando espessamento principalmente na porção de invaginação do túbulo glandular. PAS. B) Endometrose ativa destrutiva. Fibras de colágeno tipo IV da membrana basal com áreas de descontinuidade. C) Endometrose inativa. Imunomarcação discreta de uma monocamada de miofibroblastos positivos para $\alpha$-SMA. D) Endometrose ativa destrutiva. Imunomarcação intensa de múltiplas camadas de miofibroblastos, positivas para $\alpha$-SMA. Revelação: DAB, contracoloração com hematoxilina. 


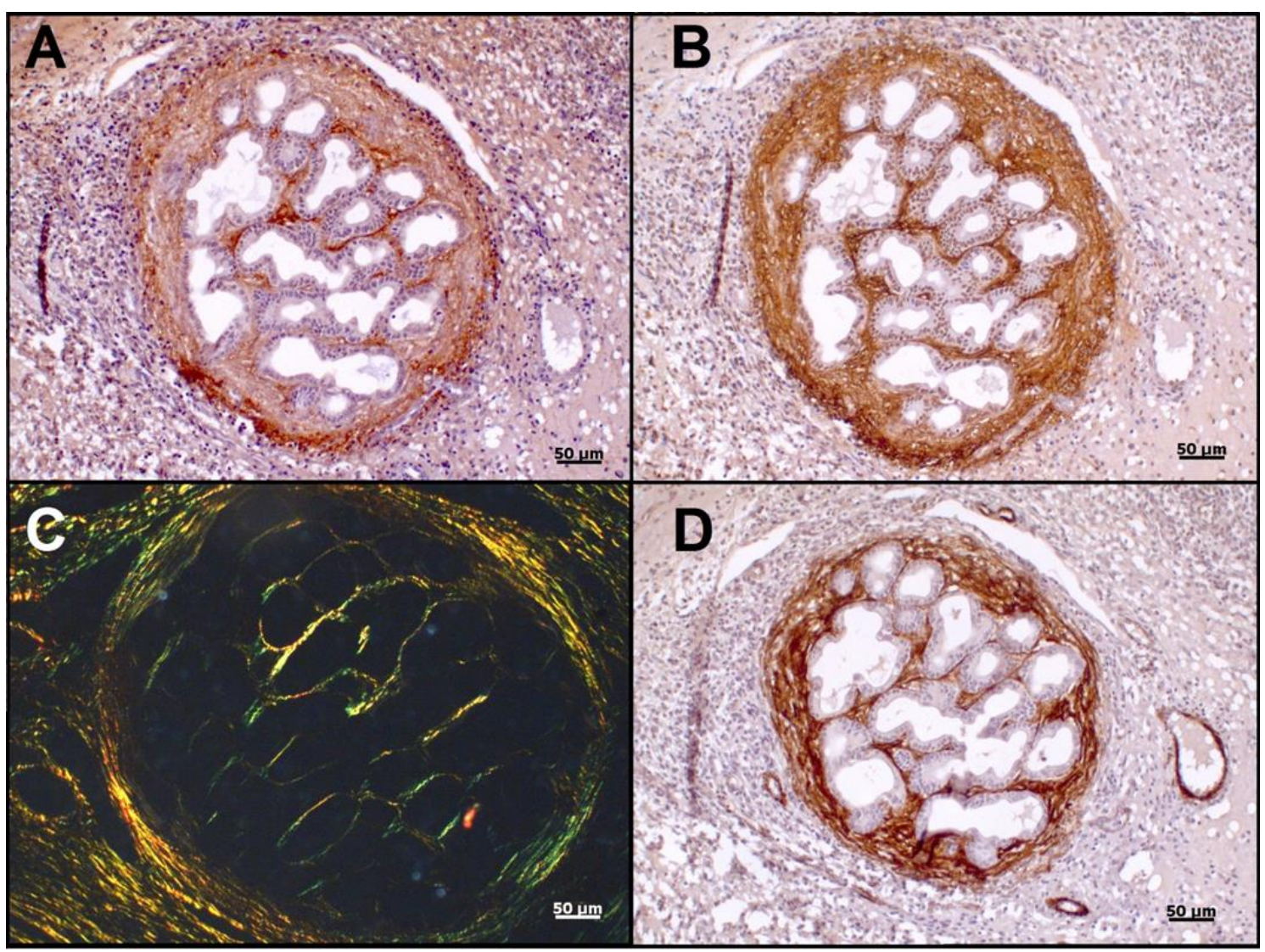

Figura 2. Fotomicrografias de endométrio equino. Endometrose ativa destrutiva. Comparativo entre técnicas imuno-histoquímicas e picrosirius red sob luz polarizada. A) Colágeno tipo I: imunomarcação positiva em todo o tecido fibrótico que envolve o ninho, com intensidade acentuada na região delimitadora e na porção central interna. B) Colágeno tipo III: expressão positiva uniformemente acentuada em todo o ninho fibrótico. C) Picrosirius Red sob luz polarizada: fibras amareladas de colágeno denso nas regiões central e periférica, correspondentes à imunomarcação de colágeno tipo I. Fibras esverdeadas de colágeno frouxo predominantes no ninho fibrótico, refletindo o observado na imunohistoquímica do colágeno tipo III. D) $\alpha$-SMA: imunomarcação acentuada de cinco camadas de miofibroblastos. Revelação: DAB, contracoloração com hematoxilina.

Com base nesses achados, postulou-se que as endometroses ativas representam um processo fibrótico de características morfológicas e funcionais distintas das endometroses inativas. Isso se explica pelo envolvimento importante dos miofibroblastos, células metabolicamente ativas de alta capacidade pró-inflamatória e fibrogênica, nas endometroses ativas, que, por sua vez, estão relacionados à deposição de colágeno tipo III, frouxo, e ao aumento da espessura da membrana basal. As endometroses inativas demonstraram uma baixa expressão de $\alpha$-SMA pelas células que circundam os ninhos fibróticos e estão relacionadas ao colágeno tipo I, denso, mantendo a espessura da membrana basal. Então, entende-se que os fatores envolvidos nesses tipos de fibroses não estejam vinculados aos miofibroblastos, mas a outros fatores não elucidados até o momento. A predominância de colágeno tipo I em $16,67 \%$ das endometroses ativas e a de colágeno tipo III em $25 \%$ das endometroses inativas podem estar relacionadas ao processo de desenvolvimento e evolução do processo fibrótico, em que há a substituição gradativa do tipo de colágeno frouxo pelo denso.

\section{CONCLUSÕES}

As fibras de colágeno denso correspondem ao colágeno tipo I, predominantes nas endometroses inativa e inativa destrutiva, enquanto as fibras de colágeno frouxo correspondem ao colágeno tipo 
III, predominantes nas endometroses ativa e ativa destrutiva. Esses dois tipos de endometrose, especialmente a ativa destrutiva, possuem uma maior quantidade de miofibroblastos periglandulares que as endometroses inativa $\mathrm{e}$ inativa destrutiva. Portanto, os miofibroblastos estão fortemente relacionados aos processos ativos, atuando na deposição de colágeno tipo III nos ninhos fibróticos. Em contrapartida, o desenvolvimento dos processos inativos não estão vinculados diretamente aos miofibroblastos, mas a outros fatores ainda desconhecidos, sendo fundamental a realização de novos estudos para o seu entendimento.

\section{AGRADECIMENTOS}

À Coordenação de Aperfeiçoamento de Pessoal de Nível Superior (Capes) e à Fundação de Amparo à Pesquisa do Estado de São Paulo, (Fapesp), pelo auxílio financeiro concedido para a aquisição de recursos para execução do experimento.

\section{REFERÊNCIAS}

EVANS, T.J.; MILLER, M.A.; GANJAM, V.K. et al. Morphometric analysis of endometrial periglandular fibrosis in mares. Am. J. Vet. Res., v.59, p.1209-1214, 1998.

HANADA, M.; MAEDA, Y.; OIKAWA, M. Histopathological characteristics of endometrosis in throughbred mares in Japan: results from 50 necropsy cases. J. Equine Vet. Sci., v.25, p.45$52,2014$.

HANAMURA, N.; YOSHIDA, T.; MATSUMOTO, E. et al. Expression of fibronectin and tenascin-c mRNA by myofibroblasts, vascular cells and epithelial cells in human colon adenomas and carcinomas. Int. J. Cancer, v.73, p.10-15, 1997.
HOFFMANN, C.; ELLENBERGER, C.; MATTOS, R.C. et al. The equine endometrosis: new insights into the pathogenesis. Anim. Reprod. Sci., v.111, p.261-278, 2009.

JUNQUEIRA, L.C.U.; COSSERMELLI, W.; BRENTANI, R.R. Differential staining of collagens type I, II and III by Sirius Red and polarization microscopy. Arch. Histol. Jpn., v.41, p.267-274, 1978.

KENNEY, R.M.; DOIG, P.A. Equine endometrial biopsy. in: MORROW, D.A. (Ed.). Theriogenology. Philadelphia: WB Saunders, 1986. p.723-729.

MANSOUR, G.D.; HENRY, M.; FERREIRA, A.M.R. Immunohistochemical study of equine endometrial extracellular matrix during the oestrous cycle. J. Comp. Pathol., v.129, p.316319, 2003.

PETROV, V.V.; FAGARD, R.H.; LIJNEN, P.J. Stimulation of collagen production by transforming growth factor- $\beta 1$ during differentiation of cardiac fibroblasts to myofibroblasts. Hypertension, v.39, p.258-263, 2002.

RICKETTS, S.W.; ALONSO, S. The effect of age and parity on the development of equine chronic endometrial disease. Equine Vet. J., v.23, p.189-192, 1991.

SAPPINO, A.P.; SCHÜRCH, W.; GABBIANI, G. Biology of disease. Differentiation repertoire of fibroblastic cells: expression of cytoskeletal proteins as a marker of phenotypic modulations. Lab. Invest., v.63, p.144-161, 1990.

STATISTICAL analysis system. Version 9.3. Cary: SAS Institute, 2011.

WALTER, I.; HANDLER, J.; REIFINGER, M. et al. Association of endometrosis in horses with differentiation of periglandular myofibroblasts and changes of extracellular matrix proteins. Reproduction, v.121, p.581-586, 2001. 